\title{
Convergence analysis of a multi-step iteration for a finite family of asymptotically quasi-nonexpansive mappings
}

\author{
Muhammad Aqeel Ahmad Khan*
}

\section{"Correspondence:}

itsakb@hotmail.com

Department of Mathematics, The

Islamia University of Bahawalpur,

Bahawalpur, 63100, Pakistan

\begin{abstract}
This paper is a continuation of the analysis of classical Kuhfittig iteration involving a finite family of asymptotically quasi-nonexpansive mappings in the general setup of uniformly convex hyperbolic spaces. We establish strong and $\triangle$-convergence results of Kuhfittig iteration, which subsequently help to apply proof mining techniques for the extraction of rates of metastability in the sense of Tao. Additionally, our proposed convergence results extend and improve various results in the current literature.

MSC: Primary 47H09; 47H10; secondary 49M05

Keywords: asymptotically nonexpansive mapping; Kuhfittig iteration; common fixed point; strong convergence; $\triangle$-convergence; modulus of uniform convexity; hyperbolic space
\end{abstract}

\section{Introduction}

Most of the problems in various disciplines of science are nonlinear in nature, whereas fixed point theory proposed in the setting of normed linear spaces or Banach spaces majorly depends on the corresponding linear structures of those spaces. A nonlinear framework for fixed point theory is a metric space embedded with a 'convex structure.' It is remarked that the non-positively curved spaces play a significant role in many branches of mathematics. The class of hyperbolic spaces - nonlinear in nature - is prominent among non-positively curved spaces and provides rich geometrical structures for different results with applications in topology, graph theory, multivalued analysis and metric fixed point theory. The study of hyperbolic spaces has been largely motivated and dominated by questions about hyperbolic groups, one of the main objects of study in geometric group theory.

Throughout this paper, we work in the setting of hyperbolic spaces introduced by Kohlenbach [1] which is more restrictive than the hyperbolic type introduced in [2] and more general than the concept of hyperbolic space in [3].

A hyperbolic space is a metric space $(X, d)$ together with a mapping $W: X^{2} \times[0,1] \rightarrow X$ satisfying

(1) $d(u, W(x, y, \alpha)) \leq \alpha d(u, x)+(1-\alpha) d(u, y)$,

(2) $d(W(x, y, \alpha), W(x, y, \beta))=|\alpha-\beta| d(x, y)$,

(3) $W(x, y, \alpha)=W(y, x,(1-\alpha))$,

(4) $d(W(x, z, \alpha), W(y, w, \alpha)) \leq(1-\alpha) d(x, y)+\alpha d(z, w)$

o 2013 Khan; licensee Springer. This is an Open Access article distributed under the terms of the Creative Commons Attribution License (http://creativecommons.org/licenses/by/2.0), which permits unrestricted use, distribution, and reproduction in any medium, provided the original work is properly cited. 
for all $x, y, z, w \in X$ and $\alpha, \beta \in[0,1]$. A nonempty subset $K$ of a hyperbolic space $X$ is convex if $W(x, y, \alpha) \in K$ for all $x, y \in K$ and $\alpha \in[0,1]$. The class of hyperbolic spaces contains normed spaces and convex subsets thereof, the Hilbert ball equipped with the hyperbolic metric [4], $\mathbb{R}$-trees, Hadamard manifolds as well as CAT(0) spaces in the sense of Gromov (see [5] for a detailed treatment).

The following example accentuates the importance of hyperbolic spaces.

Let $B_{H}$ be an open unit ball in a complex Hilbert spaces $(H,\langle\cdot\rangle)$ w.r.t. the metric

$$
k_{B_{H}}(x, y):=\arg \tanh (1-\sigma(x, y))^{\frac{1}{2}}
$$

where

$$
\sigma(x, y)=\frac{\left(1-\|x\|^{2}\right)\left(1-\|x\|^{2}\right)}{|1-\langle x, y\rangle|^{2}} \quad \text { for all } x, y \in B_{H}
$$

Then $\left(B_{H}, k_{B_{H}}, W\right)$ is a hyperbolic space where $W(x, y, \alpha)$ defines a unique point $z$ in a unique geodesic segment $[x, y]$ for all $x, y \in B_{H}$. The above example is of importance for metric fixed point theory of holomorphic mappings which are $k_{B_{H}}$-nonexpansive. For a detailed discussion of the topic, we refer to [6].

A hyperbolic space is uniformly convex [7] if for any $r>0$ and $\epsilon \in(0,2]$, there exists a $\delta \in(0,1]$ such that for all $u, x, y \in X$, we have

$$
d\left(W\left(x, y, \frac{1}{2}\right), u\right) \leq(1-\delta) r
$$

provided $d(x, u) \leq r, d(y, u) \leq r$ and $d(x, y) \geq \epsilon r$.

A map $\eta:(0, \infty) \times(0,2] \rightarrow(0,1]$, which provides such a $\delta=\eta(r, \epsilon)$ for given $r>0$ and $\epsilon \in(0,2]$, is known as a modulus of uniform convexity of $X$. We call $\eta$ monotone if it decreases with $r$ (for a fixed $\epsilon$ ), i.e., $\forall \epsilon>0, \forall r_{2} \geq r_{1}>0\left(\eta\left(r_{2}, \epsilon\right) \leq \eta\left(r_{1}, \epsilon\right)\right.$ ).

Let $K$ be a nonempty subset of a metric space $(X, d)$, and let $T$ be a self-mapping on $K$. Denote by $F(T)=\{x \in K: T(x)=x\}$ the set of fixed points of $T$. A self-mapping $T$ on $K$ is said to be:

(i) nonexpansive if $d(T x, T y) \leq d(x, y)$ for $x, y \in K$;

(ii) quasi-nonexpansive if $d(T x, p) \leq d(x, p)$ for $x \in K$ and for $p \in F(T) \neq \emptyset$;

(iii) asymptotically nonexpansive [8] if there exists a sequence $k_{n} \subset[0, \infty)$ and

$$
\lim _{n \rightarrow \infty} k_{n}=0 \text { and } d\left(T^{n} x, T^{n} y\right) \leq\left(1+k_{n}\right) d(x, y) \text { for } x, y \in K, n \geq 1
$$

(iv) asymptotically quasi-nonexpansive if there exists a sequence $k_{n} \subset[0, \infty)$ and $\lim _{n \rightarrow \infty} k_{n}=0$ and $d\left(T^{n} x, p\right) \leq\left(1+k_{n}\right) d(x, p)$ for $x \in K, p \in F(T), n \geq 1 ;$

(v) uniformly $L$-Lipschitzian if there exists a constant $L>0$ such that $d\left(T^{n} x, T^{n} y\right) \leq L d(x, y)$ for $x, y \in K$ and $n \geq 1$.

It follows from the above definitions that a nonexpansive mapping is quasi-nonexpansive and that an asymptotically nonexpansive mapping is asymptotically quasi-nonexpansive. Moreover, an asymptotically nonexpansive mapping is uniformly $L$-Lipschitzian. However, the converse of these statements is not true, in general.

The fixed point property (fpp) of various nonlinear mappings has relevant applications in many branches of nonlinear analysis and topology. On the other hand, there are certain situations where it is hard to derive conditions for the (fpp) of certain nonlinear mappings. 
In such situations, the approximate fixed point property (afpp) is more desirable. Moreover, in a nonlinear domain, the (afpp) of various generalization nonexpansive mappings is still being developed.

The problem of finding a common fixed point of a finite family of nonlinear mappings acting on a nonempty convex domain often arises in applied mathematics, for instance, in convex minimization problems and systems of simultaneous equations. A fundamental result in the construction of common fixed points of a finite family of nonexpansive mappings is essentially due to Kuhfittig [9]. The following iteration is a translation of classical Kuhfittig iteration for a finite family of nonexpansive mappings in hyperbolic spaces.

Let $U_{0}=I$, define

$$
\begin{aligned}
& U_{1} x=W\left(x, T_{1} U_{0} x, \lambda\right), \\
& U_{2} x=W\left(x, T_{2} U_{1} x, \lambda\right), \\
& \vdots \\
& U_{k} x=W\left(x, T_{k} U_{k-1} x, \lambda\right),
\end{aligned}
$$

where $\delta \leq \lambda \leq 1-\delta$ for some $\delta \in(0,1)$.

Then the corresponding Kuhfittig iteration in a compact form is defined as follows:

$$
x_{0} \in K, \quad x_{n+1}=W\left(x_{n}, T_{k} U_{k-1} x_{n}, \lambda\right), \quad n \geq 0 .
$$

The classical Kuhfittig iteration converges strongly under the compactness condition of $K$, whereas the weak convergence is established through Opial's condition. Kuhfittig iteration is comparatively less developed for various nonlinear mappings in a more general setup of spaces with non-positive sectional curvature such as hyperbolic spaces. To the best of our knowledge, Kuhfittig iteration has never been used as a tool for the approximation of common fixed points of a finite family of asymptotically quasi-nonexpansive mappings. Moreover, Rhoades [10] mentioned that one can replace $\lambda$ in the Kuhfittig iteration with a sequence $\left\{\lambda_{n}\right\}$. Here a natural question arises:

Question Is Kuhfittig iteration valid for the class of asymptotically quasi-nonexpansive mappings with a general sequence of control parameters $\delta \leq \lambda_{n} \leq 1-\delta$ for some $\delta \in(0,1)$ in the general setup of hyperbolic spaces?

The purpose of this paper is to provide an affirmative answer to the above question. Our convergence results not only can be viewed as an analogue of various existing results but also improve and generalize various results in the current literature; see, for example, [11-25] and the references cited therein.

\section{Preliminaries}

We start this section with the concept of $\triangle$-convergence which is essentially due to Lim [26] in the general setting of metric spaces. In 2008, Kirk and Panyanak [27] investigated $\triangle$-convergence in $\mathrm{CAT}(0)$ spaces and showed that $\triangle$-convergence coincides with the usual weak convergence in Banach spaces. Moreover, both concepts share many useful properties in uniformly convex spaces. 
Let $\left\{x_{n}\right\}$ be a bounded sequence in a hyperbolic space $X$. For $x \in X$, define a continuous functional $r\left(\cdot,\left\{x_{n}\right\}\right): X \rightarrow[0, \infty)$ by

$$
r\left(x,\left\{x_{n}\right\}\right)=\limsup _{n \rightarrow \infty} d\left(x, x_{n}\right) .
$$

The asymptotic radius $r\left(\left\{x_{n}\right\}\right)$ of $\left\{x_{n}\right\}$ is given by

$$
r\left(\left\{x_{n}\right\}\right)=\inf \left\{r\left(x,\left\{x_{n}\right\}\right): x \in X\right\} .
$$

The asymptotic center of a bounded sequence $\left\{x_{n}\right\}$ with respect to a subset $K$ of $X$ is defined as follows:

$$
A_{K}\left(\left\{x_{n}\right\}\right)=\left\{x \in X: r\left(x,\left\{x_{n}\right\}\right) \leq r\left(y,\left\{x_{n}\right\}\right) \text { for any } y \in K\right\} .
$$

This is the set of minimizers of the functional $r\left(\cdot,\left\{x_{n}\right\}\right)$. If the asymptotic center is taken with respect to $X$, then it is simply denoted by $A\left(\left\{x_{n}\right\}\right)$. It is known that uniformly convex Banach spaces and even $\mathrm{CAT}(0)$ spaces enjoy the property that 'bounded sequences have unique asymptotic centers with respect to closed convex subsets.' The following lemma is due to Leustean [28] and ensures that this property also holds in a complete uniformly convex hyperbolic space.

Lemma 2.1 [28] Let $(X, d, W)$ be a complete uniformly convex hyperbolic space with monotone modulus of uniform convexity. Then every bounded sequence $\left\{x_{n}\right\}$ in $X$ has a unique asymptotic center with respect to any nonempty closed convex subset $K$ of $X$.

Recall that a sequence $\left\{x_{n}\right\}$ in $X$ is said to $\Delta$-converge to $x \in X$ if $x$ is the unique asymptotic center of $\left\{u_{n}\right\}$ for every subsequence $\left\{u_{n}\right\}$ of $\left\{x_{n}\right\}$. In this case, we write $\Delta-\lim _{n} x_{n}=x$ and call $x$ the $\Delta$-limit of $\left\{x_{n}\right\}$. A sequence $\left\{x_{n}\right\}$ is said to be quasi-Fejér monotone w.r.t. a set $K$ if $d\left(x_{n+1}, x\right) \leq d\left(x_{n}, x\right)+\epsilon_{n}$ for all $x \in K$ and $\epsilon_{n} \geq 0$ for all $n \geq 0$. This concept generalizes the classical concept of Fejér monotone sequence in a sense that it satisfies the standard Fejér monotonicity property within an additional error term $\epsilon_{n}$. A mapping $T: K \rightarrow K$ is semi-compact if every bounded sequence $\left\{x_{n}\right\} \subset K$ satisfying $d\left(x_{n}, T x_{n}\right) \rightarrow 0$ has a convergent subsequence.

In the sequel, we need the following useful results.

Lemma 2.2 [29] Let $(X, d, W)$ be a uniformly convex hyperbolic space with monotone modulus of uniform convexity $\eta$. Let $x \in X$ and $\left\{\alpha_{n}\right\}$ be a sequence in $[a, b]$ for some $a, b \in(0,1)$. If $\left\{x_{n}\right\}$ and $\left\{y_{n}\right\}$ are sequences in $X$ such that $\lim _{\sup _{n \rightarrow \infty}} d\left(x_{n}, x\right) \leq c, \lim _{\sup _{n \rightarrow \infty}} d\left(y_{n}, x\right) \leq c$ and $\lim _{n \rightarrow \infty} d\left(W\left(x_{n}, y_{n}, \alpha_{n}\right), x\right)=$ c for some $c \geq 0$, then $\lim _{n \rightarrow \infty} d\left(x_{n}, y_{n}\right)=0$.

Lemma 2.3 [29] Let $K$ be a nonempty closed convex subset of a uniformly convex hyperbolic space, and let $\left\{x_{n}\right\}$ be a bounded sequence in $K$ such that $A\left(\left\{x_{n}\right\}\right)=\{y\}$ and $r\left(\left\{x_{n}\right\}\right)=\rho$. If $\left\{y_{m}\right\}$ is another sequence in $K$ such that $\lim _{m \rightarrow \infty} r\left(y_{m},\left\{x_{n}\right\}\right)=\rho$, then $\lim _{m \rightarrow \infty} y_{m}=y$.

Lemma 2.4 [11] Let $\left\{a_{n}\right\}$ and $\left\{b_{n}\right\}$ be two sequences of non-negative real numbers such that $\sum_{n=1}^{\infty} b_{n}<\infty$. If $a_{n+1} \leq\left(1+b_{n}\right) a_{n}, n \geq 1$, then $\lim _{n \rightarrow \infty} a_{n}$ exists. 


\section{Main results}

Throughout this section, we assume that the mappings $\left\{U_{n(i)}\right\}_{i=1}^{k}$ are nonexpansive and satisfy $F:=\left(\bigcap_{i=1}^{k} F\left(T_{i}\right)\right) \cap\left(\bigcap_{i=1}^{k} F\left(U_{n(i)}\right)\right) \neq \emptyset$. We are now in a position to prove our main convergence results.

Theorem 3.1 Let $K$ be a nonempty closed convex subset of a complete uniformly convex hyperbolic space $X$ with monotone modulus of uniform convexity $\eta$, and let $\left\{T_{i}\right\}_{i=1}^{k}$ be a finite family of uniformly L-Lipschitzian asymptotically quasi-nonexpansive self-mappings of $K$ with a sequence $\left\{t_{n}\right\} \subset[1, \infty)$ such that $\lim _{n \rightarrow \infty} t_{n}=1$ and $\sum_{n=1}^{\infty}\left(t_{n}-1\right)<\infty$. Assume that $F \neq \emptyset$, then the sequence $\left\{x_{n}\right\}$ defined as

$$
x_{0} \in K, \quad x_{n+1}=W\left(x_{n}, T_{k}^{n} U_{n(k-1)} x_{n}, \lambda_{n}\right), \quad n \geq 0,
$$

$\triangle$-converges to a common fixed point of $\left\{T_{i}\right\}_{i=1}^{k}$.

Proof Let $p \in F$, then observe that

$$
\begin{aligned}
& d\left(x_{n+1}, p\right)=d\left(W\left(x_{n}, T_{k}^{n} U_{n(k-1)} x_{n}, \lambda_{n}\right), p\right) \\
& \leq\left(1-\lambda_{n}\right) d\left(x_{n}, p\right)+\lambda_{n} d\left(T_{k}^{n} U_{n(k-1)} x_{n}, p\right) \\
& \leq\left(1-\lambda_{n}\right) d\left(x_{n}, p\right)+\lambda_{n} t_{n} d\left(U_{n(k-1)} x_{n}, p\right) \\
& =\left(1-\lambda_{n}\right) d\left(x_{n}, p\right)+\lambda_{n} t_{n} d\left(W\left(x_{n}, T_{k-1}^{n} U_{n(k-2)} x_{n}, \lambda_{n}\right), p\right) \\
& \leq\left(1-\lambda_{n}^{2}\right) t_{n} d\left(x_{n}, p\right)+\lambda_{n}^{2} t_{n} d\left(T_{k-1}^{n} U_{n(k-2)} x_{n}, p\right) \\
& \leq\left(1-\lambda_{n}^{k-1}\right) t_{n}^{k-2} d\left(x_{n}, p\right)+\lambda_{n}^{k-1} t_{n}^{k-2} d\left(T_{1}^{n} x_{n}, p\right) \\
& \leq\left(1-\lambda_{n}^{k-1}\right) t_{n}^{k-2} d\left(x_{n}, p\right)+\lambda_{n}^{k-1} t_{n}^{k-1} d\left(x_{n}, p\right) \\
& =t_{n}^{k-1} d\left(x_{n}, p\right) \text {. }
\end{aligned}
$$

Since $\sum_{n=1}^{\infty}\left(t_{n}^{k-1}-1\right)<\infty$, therefore Lemma 2.4 implies that $\left\{d\left(x_{n}, p\right)\right\}_{n=1}^{\infty}$ is convergent. Consequently, this fact asserts that the sequence $\left\{d\left(x_{n}, p\right)\right\}_{n=1}^{\infty}$ is bounded. Let $M \in \mathbb{N}$ be a bound of the sequence $\left\{d\left(x_{n}, p\right)\right\}_{n=1}^{\infty}$ such that $d\left(x_{n}, p\right) \leq M$ for all $n \geq 1$. Let $t_{n}:=1+r_{n}$, then observe the following variant of estimate (3.2):

$$
\begin{aligned}
d\left(x_{n+1}, p\right) & \leq\left(1+r_{n}\right)^{k-1} d\left(x_{n}, p\right) \\
& \leq d\left(x_{n}, p\right)+\theta_{k-1} r_{n} M,
\end{aligned}
$$

where $\theta_{k-1}=\left(\begin{array}{c}k-1 \\ 1\end{array}\right)+\left(\begin{array}{c}k-1 \\ 2\end{array}\right)+\left(\begin{array}{c}k-1 \\ 3\end{array}\right)+\cdots+\left(\begin{array}{c}k-1 \\ k-1\end{array}\right)$ and $\theta_{k-1} r_{n} M$ is finite.

Hence, estimate (3.3) implies that $\left\{x_{n}\right\}_{n=1}^{\infty}$ is quasi-Fejér monotone w.r.t. $F$. Therefore, $\left\{x_{n}\right\}_{n=1}^{\infty}$ is bounded, and hence Lemma 2.1 implies that $\left\{x_{n}\right\}$ has a unique asymptotic center $A_{K}\left(\left\{x_{n}\right\}\right)=\{x\}$.

For the $\Delta$-convergence of $\left\{x_{n}\right\}$, we first show that the sequence $\left\{x_{n}\right\}$ is asymptotic regular w.r.t. the $k$ th-mapping $S_{k}$, that is, $\lim _{n \rightarrow \infty} d\left(x_{n}, S_{k} x_{n}\right)=0$. For this, we reason as follows. 
Since $\left\{d\left(x_{n}, p\right)\right\}_{n=1}^{\infty}$ is convergent, therefore, without loss of any generality, we can assume that

$$
\lim _{n \rightarrow \infty} d\left(x_{n+1}, p\right)=d\left(W\left(x_{n}, S_{k}^{n} x_{n}, \lambda_{n}\right), p\right)=c>0,
$$

where $S_{k}^{n}:=T_{k}^{n} U_{n(k-1)}$. The case $c=0$ is trivial. Moreover, observe that

$$
\limsup _{n \rightarrow \infty} d\left(x_{n}, p\right) \leq c \text { and } \limsup _{n \rightarrow \infty} d\left(S_{k}^{n} x_{n}, p\right) \leq c .
$$

It follows from estimates (3.4)-(3.5) and Lemma 2.2 that

$$
\lim _{n \rightarrow \infty} d\left(x_{n}, S_{k}^{n} x_{n}\right)=0 .
$$

Note that $d\left(x_{n}, x_{n+1}\right)=\lambda_{n} d\left(x_{n}, S_{k}^{n} x_{n}\right)$, therefore letting $n \rightarrow \infty$ and using (3.6), we have

$$
\lim _{n \rightarrow \infty} d\left(x_{n}, x_{n+1}\right)=0 .
$$

Now observe that

$$
\begin{aligned}
d\left(x_{n}, S_{k} x_{n}\right) & \leq d\left(x_{n}, x_{n+1}\right)+d\left(x_{n+1}, S_{k}^{n+1} x_{n+1}\right)+d\left(S_{k}^{n+1} x_{n+1}, S_{k}^{n+1} x_{n}\right)+d\left(S_{k}^{n+1} x_{n}, S_{k} x_{n}\right) \\
& \leq(1+L) d\left(x_{n}, x_{n+1}\right)+d\left(x_{n+1}, S_{k}^{n+1} x_{n+1}\right)+d\left(S_{k}^{n} x_{n}, x_{n}\right) .
\end{aligned}
$$

Taking the lim sup on both sides of the above estimate and using (3.6)-(3.7), we get the required asymptotic regularity of the $k$ th-mapping $S_{k}$, that is,

$$
\lim _{n \rightarrow \infty} d\left(x_{n}, S_{k} x_{n}\right)=0 .
$$

Let $\left\{u_{n}\right\}$ be any subsequence of $\left\{x_{n}\right\}$ with $A_{K}\left(\left\{u_{n}\right\}\right)=\{u\}$, then

$$
\lim _{n \rightarrow \infty} d\left(u_{n}, S_{k} u_{n}\right)=0
$$

Next, we show that $u \in F\left(S_{k}\right)$. For this, we define a sequence $\left\{z_{n}\right\}$ in $K$ by $z_{i}=S_{k}^{i} u$.

So, we calculate

$$
\begin{aligned}
d\left(z_{i}, u_{n}\right) & \leq d\left(S_{k}^{i} u, S_{k}^{i} u_{n}\right)+d\left(S_{k}^{i} u_{n}, S_{k}^{i-1} u_{n}\right)+\cdots+d\left(S_{k} u_{n}, u_{n}\right) \\
& \leq t_{n} d\left(u, u_{n}\right)+\sum_{i=0}^{r-1} d\left(S_{k}^{i} u_{n}, S_{k}^{i+1} u_{n}\right) .
\end{aligned}
$$

Since $S_{k}$ is uniformly $L$-Lipschitzian with the Lipschitz constant $L_{K}$, therefore, the above estimate yields

$$
d\left(z_{i}, u_{n}\right) \leq t_{n} d\left(u, u_{n}\right)+r L_{K} d\left(S_{k} u_{n}, u_{n}\right) .
$$

Taking lim sup on both sides of the above estimate and using (3.8), we have

$$
r\left(z_{i},\left\{u_{n}\right\}\right)=\limsup _{n \rightarrow \infty} d\left(z_{i}, u_{n}\right) \leq \limsup _{n \rightarrow \infty} d\left(u, u_{n}\right)=r\left(u,\left\{u_{n}\right\}\right) .
$$


This implies that $\left|r\left(z_{i},\left\{u_{n}\right\}\right)-r\left(u,\left\{u_{n}\right\}\right)\right| \rightarrow 0$ as $i \rightarrow \infty$. It follows from Lemma 2.3 that $\lim _{i \rightarrow \infty} S_{k}^{i} u=u$. As $S_{k}$ is uniformly continuous, so we get that $S_{k}(u)=S_{k}\left(\lim _{i \rightarrow \infty} S_{k}^{i} v\right)=$ $\lim _{i \rightarrow \infty} S_{k}^{i+1} u=u$. That is, $u \in F\left(S_{k}\right)$ and hence $u$ is the common fixed point of $T_{k}$ and $U_{k-1}$. Reasoning as above - by utilizing the uniqueness of asymptotic centers - we get that $x=u$. This infers that $u$ is the unique asymptotic center of $\left\{x_{n}\right\}$ for every subsequence $\left\{u_{n}\right\}$ of $\left\{x_{n}\right\}$.

To proceed further, we show that

$$
\lim _{n \rightarrow \infty} d\left(x_{n}, S_{k-1}^{n} x_{n}\right)=0
$$

where $S_{k-1}^{n}=T_{k-1}^{n} U_{n(k-2)}$.

For this, we reason as follows.

Observe that estimate (3.2) implies that

$$
d\left(x_{n+1}, p\right) \leq(1-\delta) d\left(x_{n}, p\right)+\delta t_{n} d\left(W\left(x_{n}, S_{k-1}^{n} x_{n}, \lambda_{n}\right), p\right)
$$

Applying lim inf on both sides of the above estimate and utilizing the fact that $\delta \leq \lambda_{n} \leq 1-\delta$ and $\lim _{n \rightarrow \infty} t_{n}=1$, we get that

$$
c \leq(1-\delta) c+\delta \liminf _{n \rightarrow \infty} d\left(W\left(x_{n}, S_{k-1}^{n} x_{n}, \lambda_{n}\right), p\right) .
$$

On simplification, we have

$$
c \leq \liminf _{n \rightarrow \infty} d\left(W\left(x_{n}, S_{k-1}^{n} x_{n}, \lambda_{n}\right), p\right) .
$$

On the other hand,

$$
\begin{aligned}
d\left(W\left(x_{n}, S_{k-1}^{n} x_{n}, \lambda_{n}\right), p\right) & \leq\left(1-\lambda_{n}\right) d\left(x_{n}, p\right)+\lambda_{n} d\left(S_{k-1}^{n} x_{n}, p\right) \\
& \leq\left(1-\lambda_{n}\right) d\left(x_{n}, p\right)+\lambda_{n} t_{n} d\left(x_{n}, p\right) \\
& \leq(1-\delta) d\left(x_{n}, p\right)+\delta t_{n} d\left(x_{n}, p\right) .
\end{aligned}
$$

Taking lim sup on both sides of the above estimate, we have

$$
\limsup _{n \rightarrow \infty} d\left(W\left(x_{n}, S_{k-1}^{n} x_{n}, \lambda_{n}\right), p\right) \leq c
$$

Estimates (3.9)-(3.10) collectively imply that

$$
\lim _{n \rightarrow \infty} d\left(W\left(x_{n}, S_{k-1}^{n} x_{n}, \lambda_{n}\right), p\right)=c .
$$

Further, observe that

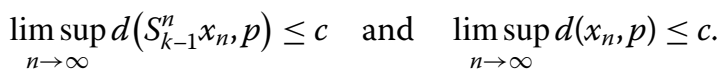

Appealing to Lemma 2.2 and utilizing estimates (3.11)-(3.12), we have

$$
\lim _{n \rightarrow \infty} d\left(x_{n}, S_{k-1}^{n} x_{n}\right)=0 .
$$


Reasoning as above, we can show that:

(i) $\lim _{n \rightarrow \infty} d\left(x_{n}, S_{k-1} x_{n}\right)=0$;

(ii) $u$ is the common fixed point of $T_{k-1}$ and $U_{k-2}$.

Continuing in a similar fashion, we can show that $u$ is the common fixed point of $S_{k-2}$ := $T_{k-2} U_{k-3}, S_{k-3}:=T_{k-3} U_{k-4}, \ldots, S_{1}:=T_{1} U_{0}$. Hence $u \in F:=\bigcap_{i=1}^{k} F\left(T_{i}\right)$. This completes the proof.

The strong convergence of iteration (3.1) can easily be established under compactness condition of $K$ or $T(K)$. Next, we give a necessary and sufficient condition for the strong convergence of iteration (3.1).

Theorem 3.2 Let $K$ be a nonempty closed convex subset of a complete uniformly convex hyperbolic space $X$ with monotone modulus of uniform convexity $\eta$, and let $\left\{T_{i}\right\}_{i=1}^{k}$ be a finite family of uniformly Lipschitzian asymptotically quasi-nonexpansive self-mappings of $K$ with a sequence $\left\{t_{n}\right\} \subset[1, \infty)$ such that $\lim _{n \rightarrow \infty} t_{n}=1$ and $\sum_{n=1}^{\infty}\left(t_{n}-1\right)<\infty$. Assume that $F \neq \emptyset$, then the sequence $\left\{x_{n}\right\}$ defined in (3.1) converges strongly to a common fixed point of $\left\{T_{i}\right\}_{i=1}^{k}$ if and only if $\liminf _{n \rightarrow \infty} d\left(x_{n}, F\right)=0$.

Proof The necessity of the conditions is obvious. Thus, we only prove the sufficiency. It follows from estimate (3.2) that $\left\{d\left(x_{n}, p\right)\right\}_{n=1}^{\infty}$ converges. Moreover, $\liminf _{n \rightarrow \infty} d\left(x_{n}, F\right)=0$ implies that $\lim _{n \rightarrow \infty} d\left(x_{n}, F\right)=0$. This completes the proof.

Since the class of asymptotically nonexpansive mappings is properly contained in the class of asymptotically quasi-nonexpansive mappings, therefore, we now list the following useful corollaries of Theorems (3.1)-(3.2).

Corollary 3.3 Let $K$ be a nonempty closed convex subset of a complete uniformly convex hyperbolic space $X$ with monotone modulus of uniform convexity $\eta$, and let $\left\{T_{i}\right\}_{i=1}^{k}$ be a finite family of uniformly Lipschitzian asymptotically nonexpansive self-mappings of $K$ with a sequence $\left\{t_{n}\right\} \subset[1, \infty)$ such that $\lim _{n \rightarrow \infty} t_{n}=1$ and $\sum_{n=1}^{\infty}\left(t_{n}-1\right)<\infty$. Assume that $F \neq \emptyset$, then the sequence $\left\{x_{n}\right\}$ defined in (3.1) $\triangle$-converges to a common fixed point of $\left\{T_{i}\right\}_{i=1}^{k}$.

Corollary 3.4 Let $K$ be a nonempty closed convex subset of a complete uniformly convex hyperbolic space $X$ with monotone modulus of uniform convexity $\eta$, and let $\left\{T_{i}\right\}_{i=1}^{k}$ be a finite family of uniformly Lipschitzian asymptotically nonexpansive self-mappings of $K$ with a sequence $\left\{t_{n}\right\} \subset[1, \infty)$ such that $\lim _{n \rightarrow \infty} t_{n}=1$ and $\sum_{n=1}^{\infty}\left(t_{n}-1\right)<\infty$. Assume that $F \neq \emptyset$, then the sequence $\left\{x_{n}\right\}$ defined in (3.1) converges strongly to a common fixed point of $\left\{T_{i}\right\}_{i=1}^{k}$ if and only if $\liminf _{n \rightarrow \infty} d\left(x_{n}, F\right)=0$.

Concluding remarks (i) Following the line of action of the results proved so far, we can prove these results with suitable changes for the following classes of nonlinear mappings:

(a) generalized asymptotically-quasi-nonexpansive mappings

(i.e., $\left\|T^{n} x-p\right\| \leq u_{n}\|x-p\|+\delta_{n}$, where $\lim _{n \rightarrow \infty} u_{n}=1$ and $\lim _{n \rightarrow \infty} \delta_{n}=0$ );

(b) asymptotically nonexpansive mappings in the intermediate sense [30]

$\left\{\right.$ i.e., $\left.\lim \sup _{n \rightarrow \infty} \sup _{x, y \in C}\left(\left\|T^{n} x-T^{n} y\right\|-\|x-y\|\right) \leq 0\right\}$.

Moreover, these proofs even hold for asymptotically weakly-quasi-nonexpansive mappings [31]. 
(ii) It is worth mentioning that Kuhfittig iteration for a finite family of nonexpansive mappings is analyzed in the general setup of uniformly convex hyperbolic spaces resulting in explicit and uniform rates of asymptotical regularity [32]; whereas for iteration (3.1), there does not seem to exist a computable rate of asymptotic regularity, let alone a rate of metastability (in the sense of Tao [33]) in cases where strong convergence holds.

Future work We intend to extract explicit and effective rates of metastability of Kuhfittig iteration involving a finite family of asymptotically quasi-nonexpansive mappings in the general setup of uniformly convex hyperbolic spaces.

\section{Competing interests}

The author declares that he has no competing interests.

\section{Acknowledgements}

The author would like to thank the editor and referees for their helpful comments and suggestions.

Received: 15 April 2013 Accepted: 20 August 2013 Published: 8 September 2013

References

1. Kohlenbach, U: Some logical metatheorems with applications in functional analysis. Trans. Am. Math. Soc. 357, 89-128 (2005)

2. Goebel, K, Kirk, WA: Iteration processes for nonexpansive mappings. In: Singh, SP, Thomeier, S, Watson, B (eds.) Topological Methods in Nonlinear Functional Analysis. Contemp. Math., vol. 21, pp. 115-123. Am. Math. Soc., Providence (1983)

3. Reich, S, Shafrir, I: Nonexpansive iterations in hyperbolic spaces. Nonlinear Anal. 15, 537-558 (1990)

4. Goebel, K, Reich, S: Uniform Convexity, Hyperbolic Geometry, and Nonexpansive Mappings. Dekker, New York (1984)

5. Bridson, M, Haefliger, A: Metric Spaces of Non-Positive Curvature. Springer, Berlin (1999)

6. Kohlenbach, U: Applied Proof Theory: Proof Interpretations and Their Use in Mathematics. Springer Monogr. Math. Springer, Berlin (2008)

7. Leustean, L: A quadratic rate of asymptotic regularity for CAT(0)-spaces. J. Math. Anal. Appl. 325, 386-399 (2007)

8. Goebel, K, Kirk, WA: A fixed point theorem for asymptotically non-expansive mappings. Proc. Am. Math. Soc. 35 , 171-174 (1972)

9. Kuhfittig, PKF: Common fixed points of nonexpansive mappings by iteration. Pac. J. Math. 97(1), 137-139 (1981)

10. Rhoades, BE: Finding common fixed point of nonexpansive mappings by iteration. Bull. Aust. Math. Soc. 62, 307-310 (2000)

11. Chang, SS, Cho, YJ, Zhou, H: Demiclosed principal and weak convergence problems for asymptotically nonexpansive mappings. J. Korean Math. Soc. 38(6), 1245-1260 (2001)

12. Chidume, CE, Ali, B: Convergence theorems for finite families of asymptotically quasi-nonexpansive mappings. J. Inequal. Appl. 2007, Article ID 68616 (2007). doi:10.1155/2007/68616

13. Fukhar-ud-din, H, Khan, AR, Khan, MAA: A new implicit algorithm of asymptotically quasi-nonexpansive mappings in uniformly convex Banach spaces. IAENG Int. J. Appl. Math. 42, 3 (2012)

14. Fukhar-ud-din, H, Khan, AR: Approximating common fixed points of asymptotically nonexpansive maps in uniformly convex Banach spaces. Comput. Math. Appl. 53, 1349-1360 (2007)

15. Gu, F, Fu, Q: Strong convergence theorems for common fixed points of multistep iterations with errors in Banach spaces. J. Inequal. Appl. 2009, Article ID 819036 (2009). doi:10.1155/2009/819036

16. Khan, AR, Domlo, AA, Fukhar-ud-din, H: Common fixed point Noor iteration for a finite family of asymptotically quasi-nonexpansive mappings in Banach spaces. J. Math. Anal. Appl. 341, 1-11 (2008)

17. Khan, AR, Khamsi, MA, Fukhar-ud-din, H: Strong convergence of a general iteration scheme in CAT(0)-spaces. Nonlinear Anal. 74, 783-791 (2011)

18. Fukhar-ud-din, $H$, Khan, MAA: Convergence analysis of a general iteration schema of nonlinear mappings in hyperbolic spaces. Fixed Point Theory Appl. (in press)

19. Osilike, MO, Aniagbosor, SC: Weak and strong convergence theorems for fixed points of asymptotically non-expansive mappings. Math. Comput. Model. 32, 1181-1191 (2000)

20. Sahin, A, Basarır, M: On the strong convergence of a modified S-iteration process for asymptotically quasi-nonexpansive mappings in a CAT(0) space. Fixed Point Theory Appl. 2013, Article ID 12 (2013) doi:10.1186/1687-1812-2013-12

21. Sahin, A, Basarır, M: On the strong convergence and $\triangle$-convergence of SP-iteration on CAT(0) space. J. Inequal. Appl. 2013, Article ID 311 (2013). doi:10.1186/1029-242X-2013-311

22. Schu, J: Weak and strong convergence to fixed points of asymptotically nonexpansive mappings. Bull. Aust. Math Soc. 43, 153-159 (1991)

23. Schu, J: Iterative construction of fixed points of asymptotically nonexpansive mappings. J. Math. Anal. Appl. 158, 407-413 (1991)

24. Tan, KK, Xu, HK: Fixed point iteration process for asymptotically nonexpansive mappings. Proc. Am. Math. Soc. 122(3), 733-739 (1994) 
25. Yao, Y, Liou, Y-C: New iterative schemes for asymptotically quasi-nonexpansive mappings. J. Inequal. Appl. 2010, Article ID 934692 (2010). doi:10.1155/2010/934692

26. Lim, TC: Remarks on some fixed point theorems. Proc. Am. Math. Soc. 60, 179-182 (1976)

27. Kirk, W, Panyanak, B: A concept of convergence in geodesic spaces. Nonlinear Anal. 68, 3689-3696 (2008)

28. Leustean, L: Nonexpansive iterations in uniformly convex W-hyperbolic spaces. In: Leizarowitz, A, Mordukhovich, BS Shafrir, I, Zaslavski, A (eds.) Nonlinear Analysis and Optimization I: Nonlinear Analysis. Contemporary Mathematics, vol. 513, pp. 193-209. Am. Math. Soc., Providence (2010)

29. Khan, AR, Fukhar-ud-din, H, Khan, MAA: An implicit algorithm for two finite families of nonexpansive maps in hyperbolic spaces. Fixed Point Theory Appl. 2012, Article ID 54 (2012). doi:10.1186/1687-1812-2012-54

30. Bruck, R, Kuczumow, T, Reich, S: Convergence of iterates of asymptotically nonexpansive mappings in Banach space with uniform Opial property. Colloq. Math. 65(2), 169-179 (1993)

31. Kohlenbach, U, Lambov, B: Bounds on iterations of asymptotically quasi-nonexpansive mappings. In: Garcia Falset, J et al. (eds.) International Conference on Fixed Point Theory and Applications (Valencia, 2003), pp. 143-172. Yokohama Publishers, Yokohama (2004)

32. Khan, MAA, Kohlenbach, U: Bounds on Kuhfittig's iteration schema in uniformly convex hyperbolic spaces. J. Math. Anal. Appl. 403, 633-642 (2013)

33. Tao, T: Soft analysis, hard analysis, and the finite convergence principle. In: Structure and Randomness: Pages from Year One of a Mathematical Blog, vol. 298. Am. Math. Soc., Providence (2008)

doi:10.1186/1029-242X-2013-423

Cite this article as: Khan: Convergence analysis of a multi-step iteration for a finite family of asymptotically quasi-nonexpansive mappings. Journal of Inequalities and Applications 2013 2013:423.

\section{Submit your manuscript to a SpringerOpen ${ }^{\circ}$ journal and benefit from:}

- Convenient online submission

- Rigorous peer review

- Immediate publication on acceptance

Open access: articles freely available online

- High visibility within the field

- Retaining the copyright to your article 